\title{
El campo discursivo del pasado reciente en el Uruguay. Entre la Teoría de los dos demonios y la perspectiva del Terrorismo de Estado*
}

\author{
Sylvia Fabiana Larrobla*
}

\section{Resumen}

El presente artículo aborda los distintos trayectos narrativos que se configuraron en torno a la última dictadura cívico-militar en el Uruguay (1973-1985), delineando un campo discursivo que aún se debate entre la teoría de los dos demonios y la perspectiva del Terrorismo de Estado.

El abordaje de este recorrido nos permitirá dar cuenta de las variaciones discursivas conforme el contexto político se modificaba, así como el intento, aún inconcluso, por parte de los gobiernos progresistas, de construir una narrativa consensuada, intentando articular elementos de los distintos relatos producidos desde la recuperación democrática.

\section{Palabras clave}

Memoria - Discurso - Dictadura.

\section{Abstract}

* Artículo recibido el 11de junio de 2013. Aceptado el 15 de agosto de 2013.

* Licenciada en Ciencias Políticas. Facultad de Humanidades y Ciencias de la Educación. UdelaR (Uruguay). Candidata a Magíster en Ciencias Sociales y Humanidades (Univ. Nacional de Quilmes).

Contacto: fabianalarro@gmail.com 
This article discusses the various narrative paths that are configured around the civic-military dictatorship in Uruguay (1973-1985), outlining a discursive field still debate between the theory of the two demons and the prospect of Terrorism State. The approach of this course will allow us to account for discursive variations as the political context was modified and the attempt, still incomplete, by progressive governments agreed to build a narrative, trying to articulate the different elements produced from the recovery stories democratic.

\section{Keywords}

Memory - Speech - Dictatorship.

Al igual que ha sucedido en otros países de la región, Uruguay se ha visto enfrentado a disputas políticas en torno a las representaciones sobre su pasado reciente. En un país que se forjó en la promoción de valores vinculados con el sujeto ciudadano, donde no se reconocían fracturas posibles sino solo diferencias que podían resolverse pacíficamente sin alterar la institucionalidad democrática, la dictadura resultó un quiebre inimaginable para la mayoría de la población, en la medida en que cuestionó fuertemente el imaginario social ${ }^{1}$ construido durante la primera mitad del siglo XX.

Este quiebre de la institucionalidad, que había sido precedido de un lento pero seguro avance autoritario en el marco de gobiernos democráticos, supuso a su vez el quiebre de la narración única y consensuada sobre quiénes y cómo son los uruguayos. Memorias $^{2}$ e identidades se imbrican y se interconectan profundamente; son construcciones subjetivas determinadas, entre otras cosas, por el contexto histórico de su producción; la alteración de una ellas impacta en la otra y produce resistencias y confrontaciones, la búsqueda de "una memoria nacional única" en la cual, desde el

\footnotetext{
${ }^{1}$ Podemos señalar como algunos de los rasgos distintivos de este imaginario los siguientes: la excepcionalidad uruguaya frente al resto del continente, el mito del consenso y la exaltación del respeto a las leyes, la existencia de una sociedad homogénea e hiperintegrada, etc. Sobre el tema ver: Rama, Germán (1987) La democracia en Uruguay. Buenos Aires: Grupo Editor Latinoamericano; Rial, Juan (1987) El imaginario social. Los mitos políticos y utopías en el Uruguay. Cambios y permanencias durante y después del autoritarismo. En Sosnowski, Saúl (comp.) Represión, exilio, y democracia: la cultura uruguaya. Montevideo: Ediciones de la Banda Oriental.

2Cuando digo "memoria" estoy haciendo referencia a las "memorias socialmente construidas y compartidas, como afirma Jelin: "(...) memorias compartidas, superpuestas, producto de interacciones múltiples, encuadradas en marcos sociales y en relaciones de poder (...)" (Jelin, 2001, p. 22).
} 
Estado, se insta a olvidar algunos sucesos y recordar otros, es planteada casi como una condición necesaria para la supervivencia como país y como nación. ${ }^{3}$

Lo anterior permite pensar que el tema de la violación de los Derechos Humanos ha interpelado tan profundamente nuestra matriz identitaria, que para muchos actores no hay otra manera de construir un proyecto común más que el olvido o la ubicación definitiva en el "pasado-pasado" de este tema.

Así es que desde la reinstalación del régimen democrático en el Uruguay, en marzo de 1985, el abordaje del pasado reciente vinculado con la violación de los derechos humanos fue construyéndose en torno a narrativas diversas, unas provenientes de las élites gubernamentales, que buscaban recomponer una identidad rota y cuestionada, buscando un "encuadramiento de la memoria" (Pollak, 2000, p. 25) y otras, promovidas y erigidas como alternativas desde buena parte de los sectores de izquierda nucleados en su gran mayoría dentro del Frente Amplio y, sobre todo, desde los organismos de derechos humanos. Estos últimos, cuyo actor más relevante es la Asociación de Madres y Familiares de detenidos-desaparecidos ${ }^{4}$, se constituyeron en un agente de memoria sosteniendo un discurso que pugnaba por legitimarse frente a una narrativa oficial que se esmeraba en estigmatizar y culpabilizar los reclamos producidos por estos actores.

En el presente artículo intentaré bosquejar el trayecto de estos discursos abordando los dos grandes campos narrativos: el que se origina a partir de las élites gubernamentales durante la transición democrática, que incorpora elementos del discurso militar, y el que promueven los movimientos sociales, sobre todo aquellos vinculados con la lucha por la verdad y la justicia, reconociendo que en el interior de cada uno de estos campos confluyen y se superponen diversos relatos que también se disputan la legitimidad de la visión sobre el pasado reciente.

Siguiendo con los recorridos discursivos, culminaré dando cuenta del intento por parte de los gobiernos progresistas, a partir de 2004, de construir una narrativa consensuada, que incorpore y contenga elementos de los distintos relatos producidos desde 1985.

\section{La transición democrática. Sanguinetti y el discurso de la pacificación. La teoría de los dos demonios}

Una de las características reconocidas de la transición uruguaya fue la salida negociada entre los actores políticos y los militares, lo que - entre otras cosas- puso

\footnotetext{
3 Ernest Rénan decía que el error histórico y el olvido eran necesarios para la construcción de la Nación [En: ¿Qué es una nación?, Alianza Editorial, Madrid. 1987]. En ese sentido, también Paul Ricoeur hace mención del olvido intencional como mecanismo de reelaboración del pasado [En: La memoria, la historia, el olvido, FCE, Bs. As. 2008.]

${ }^{4}$ Es importante mencionar al Servicio de Paz y Justicia, a la comisión de Derechos Humanos del Plenario Intersindical de Trabajadores-Convención Nacional de Trabajadores (PIT-CNT) y más recientemente, desde su creación, a la Asociación de ex presos políticos CRYSOL.
} 
de relieve el peso político que las Fuerzas Armadas tenían en ese momento y la influencia que ejercían no solo sobre el sistema político que comenzaba a reconfigurarse, sino también sobre una ciudadanía que aún $-\mathrm{y}$ por algunos años más - sentía la amenaza de un posible retorno militar.

Durante la dictadura los militares construyeron la justificación de su accionar desde una perspectiva de guerra según la cual la ruptura institucional y la represión fueron herramientas en "defensa de la democracia", que era atacada por los "enemigos" calificados de "antinacionales". Esta perspectiva se acompañaba de la apelación a la memoria a través del uso de una frase que invadía los medios audiovisuales y gráficos: "Aquel pueblo que olvida su pasado, está condenado a repetirlo".

Gran parte de la población aceptó esta narrativa y la hizo propia, de alguna manera la incorporó a su vida y a sus propios relatos de lo sucedido, y una vez que se avanzó en la etapa transicional hacia la democracia, esta narrativa militar no desapareció, sino que se transformó y trasvasó los límites temporales de la dictadura, colaborando y formando parte de una nueva narrativa, también oficial, estructurada en torno a los conceptos de olvido y pacificación.

La memoria a la que apelaban los militares se transformó en la apelación al olvido realizada por la mayoría ganadora de las elecciones de 1984, encabezadas por Julio Ma. Sanguinetti, cuyo discurso reconciliatorio puede sintetizarse en la siguiente frase: "No se puede tener los ojos en la nuca". El presidente de la República de aquellos años lo expresa así, hoy, en su libro La Reconquista: "(...) No podemos vivir con la mente cristalizada en las luchas del pasado porque así no vamos a salir de ellas. Por el contrario, tenemos que superarlas mirando hacia adelante con espíritu de reconciliación y firmeza (...)" (Sanguinetti, 2012, p. 460).

Del anterior régimen de memoria ${ }^{5}$ (Crenzel, 2008) se mantienen algunos elementos justificativos del accionar militar, dotándolo de una continuidad que favorece su consolidación hegemónica en tanto acompaña una transición que, como ya se señaló, fue negociada y acordada.

La construcción de este nuevo régimen de memoria se realizó desde la élite gubernamental, en la cual paulatinamente fue consolidándose la adhesión a los preceptos fundamentales de la denominada "Teoría de dos los demonios".

Según Carlos Demasi, esta teoría es una herramienta conceptual utilizada para explicar cómo la sociedad fue víctima de un conflicto entre dos fuerzas opuestas: la guerrilla y las Fuerzas Armadas, cuyo corolario inevitable fue el golpe de Estado (Demasi, 2004).

Su origen es ubicado en Argentina, durante la transición democrática, y aunque hay discusiones sobre el momento de su surgimiento (autores como Hugo Vezetti y Daniel

\footnotetext{
${ }^{5}$ Tomo este concepto de Crenzel, entendiendo que las proposiciones que estructuran la forma de evocar el pasado a su vez organizan el debate público, lo que no significa que no existan disputas sobre ellas.
} 
Feierstein afirman que sus preceptos surgieron en la década del 70), su manifestación más reconocida es el prólogo del libro Nunca Más.

En Uruguay su instauración coincide con el debate sobre la amnistía a los militares en los inicios del gobierno de Sanguinetti, argumentándose la necesidad de "equiparar" los beneficios que habían recibido los exguerrilleros ${ }^{6}$.

A partir de esto se produce una narrativa que refuerza la perspectiva del olvido y la pacificación, y que brinda una explicación tranquilizadora para la mayoría de la población. A su vez la deshistorización de los sucesos y de los actores que intervienen en ellos refuerza la idea de que lo sucedido fue simplemente una "desviación" de la historia, una guerra entre dos ejércitos, casi en igualdad de condiciones, en la cual los partidos políticos y la sociedad civil poco o nada podían hacer.

Diversos actores han acompañado esta postura, reafirmando la hegemonía de esta perspectiva: las Fuerzas Armadas la han utilizado como justificación de su comportamiento; los partidos políticos que adhieren a ella eluden su responsabilidad en el proceso de avance del autoritarismo en la medida en que se trata de un conflicto en el que no tenían posibilidad de intervenir, y la sociedad civil, a su vez, presentada como víctima inocente y espectadora pasiva y ubicándose gran parte de ella en ese lugar, evita cuestionarse e interpelarse respecto de sus niveles de responsabilidad durante la dictadura (Vezetti, 2002).

Los preceptos principales de esta "teoría" conforman un relato tranquilizador, de fácil anclaje en una sociedad que no quería interpelarse con respecto a su propio pasado. Como afirma Lucas Bietti:

El discurso del Nunca Más es un 'discurso sedante' que opera sobre todos los sectores sociales: exculpa a cómplices o responsables; disciplina y niega a los insistentes denunciadores de las violaciones de los derechos humanos; horroriza, paraliza (pero tranquiliza) al que 'jamás supo nada'. (...) El presente es así 'virginizado', ahora 'todos somos democráticos', no importa qué hayamos hecho antes. (...) El diseño temporal, el encapsulamiento del pasado, la condena de una violencia abstracta y la edificación de dicotomías son funcionales a este contexto de 'borrón y cuenta nueva' (...). (Bietti, 2008, p. 4).

\footnotetext{
${ }^{6}$ En marzo de 1985, apenas asumido el gobierno colorado, se votó una amnistía para todos los presos políticos exceptuando aquellos que habían cometido delitos de sangre, a los cuales se los reprocesó computándose cada año que habían pasado detenidos como tres. Casi enseguida, y junto con la presentación de denuncias sobre asesinatos políticos y desapariciones, comenzó a discutirse la necesidad política de votar una amnistía a los militares. Esta discusión culmina en la elaboración de un proyecto que posteriormente se transformará en ley, en el que el Estado renuncia a juzgar y condenar a aquellos militares que hayan cometido delitos y establece que solo investigará y juzgará en determinados casos, estipulados en el artículo 4to. de esta ley. Este mismo artículo será el utilizado, posteriormente, en las administraciones del Dr. Tabaré Vázquez y José Mujica, para habilitar una serie de investigaciones que incluyeron excavaciones arqueológicas en busca de restos de detenidos-desaparecidos y habilitaron la realización de juicios penales a acusados de crímenes de lesa humanidad.
} 
Este discurso, en el que el expresidente Sanguinetti resulta uno de sus principales voceros, apenas logra ser discutido por quienes pretendían mostrar una perspectiva distinta, y en esa desigualdad que da cuenta de la hegemonía de la narrativa oficial, se moldea, a su vez, la narrativa alternativa, que busca formas de hacer decible aquello que no quería ser escuchado.

El relato alternativo, entonces, comienza a configurarse desde los sectores de izquierda y desde los organismos de derechos humanos integrando diversos ejes y argumentaciones que intentan explicar, denunciar, demandar y en definitiva visibilizar aquellos que desde filas oficiales se pretendía opacar, enfatizando unos $u$ otros y mostrando más o menos diferencias en las posturas según los niveles de disputa y el contexto político por el que se estuviera transitando. Estos distintos énfasis confluyen en una narrativa que se conoce como la "narración humanitaria", en la que se hace hincapié en la calidad de víctima del sujeto, destacando el horror de los crímenes y coincidentemente con la teoría de los dos demonios- deshistorizándolo, en la medida en que se lo coloca como un tipo de víctima universal. Esta construcción se vincula con una estrategia de denuncia y reclamo de justicia que buscaba la empatía del resto de la población, intentando fisurar la hegemonía del relato de los "dos demonios".

EISu diseño implicó focalizar la atención sobre un colectivo que podía ser identificado como tal: los detenidos-desaparecidos y los niños secuestrados. A su vez las voces de los familiares y sobre todo de las madres que buscaban a sus hijos resultaba una imagen socialmente aceptada para ser escuchada en la medida en que no se la identificaba con los movimientos guerrilleros de la década del 70 , que formaban parte del "otro demonio".

Esta centralidad de la víctima desaparecida no solo supuso una omisión de la propia historia militante de quienes habían sido secuestrados, sino que también significó el relegamiento y el acallamiento de otras denuncias y demandas sobre violaciones a los derechos humanos.

Los silencios que se desplegaban respecto del pasado reciente eran diversos y provenían de distintos actores políticos y sociales, superponiéndose y configurando narraciones de olvidos y memorias cuya selección dependía del especial contexto sociopolítico que se vivió durante la transición.

Uno de esos silencios se refirió a las situaciones de detención y tortura que, habiendo sido denunciadas fuertemente en el exterior durante la dictadura, cedieron su lugar a las denuncias vinculadas con las desapariciones. En un país donde la lógica represiva se estructuró a partir del encarcelamiento masivo y la tortura, las memorias de estas así como la de los asesinatos políticos se circunscribieron a un pequeño círculo y al relato testimonial, y en algún caso obtuvieron difusión a través de los relatos épicos referidos a los rehenes del Movimiento de Liberación Nacional - Tupamaros durante la 
dictadura. ${ }^{7}$ Se configuró una memoria subterránea dentro de otra memoria también subterránea: la de los ex presos políticos, quienes, hasta hace muy poco tiempo, no consideraban relevante exigir justicia por las situaciones vividas.

Esta primera etapa de apertura democrática estuvo signada por una serie de acontecimientos políticos que condicionaron y determinaron la construcción de las distintas narrativas vinculadas con el pasado: el proceso de discusión y votación de la Ley de Caducidad de la Pretensión Punitiva del Estado ${ }^{8}$ ("Ley de impunidad"), votada por el Parlamento el 22 de diciembre de 1986, que derivó en la realización de una campaña de recolección de firmas para impedir su puesta en vigencia, y que finalmente fue ratificada a través de un plebiscito llevado a cabo el 16 de abril de 1989, por aproximadamente un 57 \% de la ciudadanía. Esta fecha de 1989, cuando la narrativa humanitaria y reivindicativa de los derechos humanos es simbólicamente derrotada, puede considerarse el inicio de un período caracterizado por el silencio y la convocatoria al olvido. La derrota del "voto verde" ${ }^{\text {, }}$, que implicó fundamentalmente el archivo de las causas judiciales penales por estar comprendidas dentro de la ley, encapsuló la narración a los ámbitos originarios de su producción: organismos de derechos humanos y algunos sectores de izquierda especialmente sensibilizados con el tema. Por otro lado, el "veredicto de las urnas", sagrado e indiscutible como ritual ciudadano de resolución de conflictos, significó para muchos el cierre definitivo de la discusión en la medida en que la ciudadanía había expresado su voluntad, y por tanto consideraron casi como un mandato explícito el desplegar un manto de silencio y olvido sobre el tema. ${ }^{10}$ Pero, como señala Jelin, el olvido nunca es ausencia, y en referencia a episodios que fracturaron imaginarios e identidades -entre otras fracturas ocurridas-, el olvido "es la representación de algo que estaba y ya no está" (Jelin, 2001, p. 9).

En este marco de disputas diversas, delimitado por una campaña electoral permanente que se extendió por casi todo el período, comenzó a perfilarse dentro de

\footnotetext{
${ }^{7}$ En el año 1973 fueron sacados del Penal de Libertad 9 integrantes de la dirección del Movimiento de Liberación Nacional - Tupamaros, quienes quedaron detenidos —en distintos cuarteles del interior del país - en calidad de rehenes. Lo mismo sucedió con un conjunto de mujeres, integrantes también del movimiento, pero su situación no fue relatada ni rescatada hasta hace muy poco tiempo, cuando por primera vez se publica una investigación realizada sobre esta experiencia, titulada "Las rehenas". Por otro lado, el MLN-T construye desde su salida de la cárcel y su ingreso en la legalidad democrática una narrativa épica sobre su pasado sobre la que no voy a detenerme en este trabajo, pero que merecía ser mencionada.

${ }^{8}$ En la nota al pie número 6 hago referencia a esta ley y su contenido más sustancial.

9 El resultado del plebiscito fue conocido como la "derrota del voto verde", haciendo referencia al color de la papeleta que impugnaba la ley de Caducidad. Por otra parte, quienes promovían su ratificación estuvieron representados por la papeleta amarilla.

${ }^{10}$ Esta postura de "tema laudado" no solo fue defendida por quienes habían apoyado y votado a favor de la ley de Caducidad, sino que también fue sostenida por muchos actores políticos relevantes que consideraban que seguir discutiendo este tema era no respetar la voluntad popular. Esta misma discusión, pero con mucho más fuerza y con conflictos importantes hacia el interior de la izquierda, surgirá durante el planteo del plebiscito de 2009 para la anulación de la misma ley.
} 
la narrativa oficial el discurso estigmatizador respecto de quienes reclamaban justicia, caracterizándolos como "revanchistas". Esta caracterización permanecerá a lo largo del tiempo y surgirá en distintos debates vinculados con los reclamos de justicia.

\section{0 - 1999: Silencios y Olvidos}

Como se señaló anteriormente, la derrota del "voto verde" significó a grandes rasgos la clausura de la discusión sobre el pasado y el fin de las movilizaciones masivas que habían promovido y defendido la impugnación de la Ley 18.848 .

SóloSolo unos pocos colectivos quedaron trabajando en silencio y acusados, ante cualquier demanda, de querer perturbar la paz luego de que la población se había pronunciado claramente a favor de esta.

Durante el gobierno del nacionalista Luis Alberto Lacalle se consolidan el silencio y la mirada acusatoria hacia todo aquel que quisiera poner en cuestión lo sucedido; el fervor militante que caracterizó el movimiento que se aglutinó en torno a la recolección de firmas y luego en la campaña a favor del voto verde fue sustituido por la resignación y el repliegue de la esfera pública.

Los organismos de Derechos Humanos y sectores políticos de izquierda involucrados fuertemente con esta temática intentaban diseñar estrategias que lograran quebrar ese horizonte de olvidos.

Finalmente, el 20 de mayo de 1996, es convocada por la Asociación de Madres y Familiares de detenidos-desaparecidos por primera vez la "Marcha del Silencio"11 a veinte años de los asesinatos de los legisladores Zelmar Michelini y Héctor Gutiérrez Ruiz en Buenos Aires, Argentina. La realización de esta primera marcha simbolizó el regreso del debate sobre el pasado reciente y la disputa por ganar cada vez más espacios de visibilidad en la esfera pública. Paulatinamente la "cuestión de los derechos humanos" volvió a ubicarse como uno de los temas centrales del debate político, pendiente de resolución. Sanguinetti había sido nuevamente elegido presidente de la República, y su mandato será recordado, en este campo, por la negativa sistemática y cerrada a brindar cualquier tipo de colaboración que posibilitara el encuentro de niños que habían sido secuestrados y sus padres desaparecidos o detenidos. ${ }^{12}$

\footnotetext{
${ }^{11}$ A partir de esta fecha la "marcha del silencio" continúa realizándose todos los años hasta el presente.

12 En este sentido, resulta paradigmático el caso de Juan Gelman y su nieta Macarena, quien había sido apropiada por un integrante de las fuerzas policiales, Mauriño, que a su vez había ejercido como jefe de Policía de San José durante el primer gobierno de Sanguinetti. Gelman le escribió al expresidente solicitando su ayuda para hallar a su nieta, ayuda que le fue negada. Una vez culminado el mandato presidencial y estando en funciones la nueva administración de gobierno, encabezada por el Dr. Jorge Batlle (del mismo partido que el Dr. Sanguinetti), la nieta de Gelman fue ubicada y restituida su identidad.
} 


\section{La administración de Jorge Batlle. La instalación de la Comisión para la Paz}

No fue sino hasta el año 2000 cuando por primera vez desde el gobierno se reconoce la necesidad de resolver el tema sin apelar al olvido como base de la reconciliación, pero continuando en la búsqueda de un "punto final" que contentara a todas las partes, configurando la imagen de un pasado en el cual la dictadura aparece como un hecho excepcional cuyos efectos pueden ser saldados y clausurados por la sola voluntad de aquellos que se erigen como los protagonistas de esa historia.

En esta línea, con el gobierno del colorado Jorge Batlle, se constituyó una comisión integrada por notables, personas reconocidas por su trayectoria en distintos movimientos sociales, denominada "Comisión para la Paz" (COMIPAZ), que vino a cumplir el rol que anteriormente habían cumplido las Comisiones de Verdad instaladas más tempranamente en otros países de la región, en el sentido que le confiere Calveiro en el artículo "Los desafíos de la memoria", cuando afirma que estas fueron intermediarias entre las distintas memorias y la "construcción de una verdad histórica que permitiera fijar un relato admisible para la sociedad" (Calveiro,2007, p. 248). ${ }^{13}$

Si bien parece no haber demasiados cambios en las narrativas, por ejemplo: la dictadura sigue presentándose como una excepcionalidad que no logra insertarse en un proceso histórico determinado y la lógica binaria de la teoría de los dos demonios sigue presente en las argumentaciones y justificaciones brindadas por distintos actores, las señales que comienzan a producirse desde la élite gobernante indican un viraje importante respecto de cómo había sido la actuación de las administraciones pasadas en referencia a este tema.

En primer lugar acontece una serie de sucesos cargados de sentido: 1) Jorge Batlle, en el trayecto que lo llevaba al Palacio Legislativo, donde iba a brindar el discurso de asunción frente a la Asamblea General, pasa frente a las Madres y Familiares de detenidos-desaparecidos y los saluda. Es el primer presidente que literalmente se detiene a mirarlas, y es el primer presidente que las recibirá luego en el edificio presidencial. 2) Establece los contactos necesarios que posibilitan el hallazgo y encuentro de Juan Gelman y su nieta Macarena. 3) Interviene como mediador para que Gerardo Vázquez, de quien Sara Méndez sospechaba que era su hijo secuestrado en 1976, se realice por su propia voluntad el análisis de ADN. ${ }^{14}$

\footnotetext{
${ }^{13}$ La autora —en el caso uruguayo - se refiere a la Comisión Investigadora sobre la Situación de Personas Desaparecidas, conformada a nivel parlamentario en el año 1985. Considero que por diversas razones esta Comisión Investigadora no puede ser equiparada a las Comisiones de Verdad que se formaron en otros países; sin embargo, la COMIPAZ, aunque tardíamente convocada, sí reúne los elementos que nos permiten referirnos a ella como una "Comisión de la Verdad".

${ }^{14}$ Sara Méndez buscó durante 26 años a su hijo. Diferentes elementos hacían presumir que se podía tratar de Gerardo Vázquez. Durante más de cinco años estuvo litigando para que fuera posible realizar el ADN que confirmara o descartara la identidad. Finalmente Gerardo Vázquez acepta su realización a pedido de
} 
En segundo lugar la instalación de la COMIPAZ configuró nuevas claves interpretativas sobre el pasado, reconociendo, por primera vez en el discurso oficial, la existencia de desaparecidos, no solo en Argentina sino también en Uruguay.

La comisión trabajó arduamente en la búsqueda de testimonios, solicitando información a las Fuerzas Armadas y elaborando, finalmente, el 10 de abril de 2003, un informe definido por la Resolución presidencial número 448, como "la versión oficial sobre la situación de los detenidos-desaparecidos". En él se incluían los nombres de aquellos ciudadanos sobre quienes - a juicio de la comisión - se habían reunido los elementos suficientes que permitían concluir que habían sido víctimas de la acción ilegal del Estado. A su vez se informaba sobre el presunto destino de los restos de los desaparecidos, que en el caso de las desapariciones ocurridas en Uruguay se indicaba que habían sido desenterrados, cremados y sus cenizas tiradas en el Río de la Plata.

Lo que es interesante rescatar, más allá del contenido del informe, es en primer lugar su pretensión de verdad ${ }^{15}$ y clausura; en segundo lugar, la focalización nuevamente en las situaciones de desaparición, excluyendo de la investigación todas las otras situaciones de muerte y violación de derechos que habían ocurrido durante la dictadura y en tercer lugar el reconocimiento de situaciones de desaparición en el territorio uruguayo.

En este sentido, los relatos de denuncia comenzaron a adquirir legitimidad fuera de los círculos donde tradicionalmente se producían, lo ocurrido en materia de violación de derechos humanos durante la dictadura dejó de ser puesto en duda; existía, ahora, un reconocimiento oficial que le otorgaba el estatus de "verdad".

Por primera vez se estableció un espacio de diálogo institucional entre actores que disputaban distintas interpretaciones del pasado; y aunque el objetivo planteado por el gobierno fue "abrir para cerrar" y se apeló nuevamente al concepto de "búsqueda de paz entre los orientales", la habilitación de ese espacio permitió legitimar, como se señaló antes, un discurso que hasta ese momento podía considerarse marginal. Por otra parte, el "punto final" ${ }^{\prime 16}$ no fue posible en tanto que las distintas estrategias planteadas por quienes se disputaban el campo de interpretaciones del pasado reciente posibilitaron la apertura de un debate que continúa desarrollándose, y permitieron que un importante sector de la sociedad, que había permanecido omiso

\footnotetext{
Jorge Batlle. El resultado es negativo. Sara Méndez encontrará a su hijo más adelante, en el año 2002, en Buenos Aries, Argentina.

${ }^{15}$ La búsqueda de la "verdad" absoluta y única parece ser un eje estructurador de las narrativas sobre el pasado reciente. Así como los movimientos activistas por los derechos humanos reclaman "la verdad", cuando el Estado se dispone a brindar alguna respuesta, lo hace, también, dentro de esa misma lógica de "la verdad de los hechos".

${ }^{16}$ Utilizo la expresión "punto final" en tanto uno de los objetivos de la Comisión para la Paz era la clausura y resolución definitiva de este tema una vez publicado su informe final. Ver: http://espectador.com/documentos/InfFinComPaz.pdf
} 
frente a las graves violaciones cometidas por el Estado, ahora se enfrentara a estas, a veces con sorpresa y otras con horror.

Esta confrontación con un pasado que había sido negado u omitido se produce, desde el lugar del espectador que se horroriza ante un espectáculo terrible, sin ubicarse él mismo en el contexto de los sucesos. La observación del horror no trae consigo nuevos relatos, que rompan con el modelo explicativo básico que consolidó la teoría de los dos demonios, pero permitió la extensión del tema en sectores donde nunca había estado presente y habilitó el flujo de información en este sentido.

\section{Los gobiernos progresistas. Tabaré Vázquez y José Mujica ${ }^{17}$}

Hasta octubre de 2004, momento en que el Frente Amplio gana por primera vez en su historia la elección nacional y accede al gobierno, dos discursos parecían oponerse: el que sostenía la teoría de los dos demonios y aquel que promovía una mirada hacia el pasado desde la perspectiva del Terrorismo de Estado. A su vez, las personas eran rápidamente clasificadas según el tipo de discurso al que adhirieran; así, quien sostenía la teoría de los dos demonios como modelo explicativo de los sucesos era colocado sin dudar a la derecha del espectro político, y viceversa.

Con el ejercicio del gobierno comienzan a hacerse visibles y cada vez más notorias las diversas miradas que la dirigencia frenteamplista tenía y tiene respecto de este tema. Las líneas de corte, paulatinamente, dejaron de ser tan claras como aparentaban ser, y las posturas que convocaban unas al olvido y otras a las memorias ya no eran elementos discriminatorios de izquierdas y derechas.

De todas formas, la asunción de un gobierno progresista supuso cambios importantes en la gestión de la problemática vinculada con la violación de los derechos humanos. ${ }^{18}$ Rápidamente podemos decir que Tabaré Vázquez aplicó una política cautelosa y cuidadosa, construyendo un discurso que no resultara molesto para la izquierda ni para los organismos de derechos humanos, los que esperaban ansiosos medidas eficaces y rápidas, pero que tampoco resultara demasiado incómoda para la oposición política. En ese sentido, buscó arduamente la construcción de un relato consensuado que pudiera poner fin a las disputas por el pasado reciente.

\footnotetext{
${ }^{17}$ Durante ambas administraciones se sucedieron una serie de acontecimientos políticos vinculados con la problemática del pasado reciente de los que no daré cuenta aquí, solamente serán mencionados si resultan pertinentes para el análisis de la narrativa. Entiendo que el contexto determina esas narrativas, y en ese sentido es que se mencionan los sucesos, pero sin profundizar en estas relaciones ni en el análisis de los acontecimientos en sí mismos, ya que trascienden los objetivos de este ensayo.

${ }^{18}$ Tabaré Vázquez aplicó el artículo 4to de la "ley de Caducidad", permitiendo el juzgamiento de los más emblemáticos torturadores. Por otro lado, habilitó, mediante un convenio con la Universidad de la República, las excavaciones arqueológicas que posibilitaron el hallazgo de restos de detenidosdesaparecidos e investigaciones históricas en archivos de inteligencia policial y militar.
} 
Esta búsqueda de la "unidad nacional" emprendida por Vázquez lo llevó a incluir en su discurso y en sus acciones elementos provenientes de narrativas diversas. Por un lado, instala el tema de las desapariciones forzadas como una problemática que le compete a toda la sociedad —rescatándolo del lugar restringido al sufrimiento familiar en el que había sido colocado- legitimando la perspectiva del terrorismo de Estado.

Por otro lado, realiza propuestas, como la instauración del "Día del Nunca Más", fuertemente criticadas por su cercanía a los preceptos de la "teoría de los dos demonios" y reinstala la idea de paz y reconciliación entre uruguayos, que hacían recordar los discursos de administraciones anteriores.

Un elemento importante de esta estrategia de intento de construcción de un relato "verdadero" y de consenso lo constituyó la realización de un convenio con la Universidad de la República, mediante el cual un equipo de historiadores de la Facultad de Humanidades y Ciencias de la Educación, previa investigación en distintos archivos documentales de la época de la dictadura, elaboró un informe en formato libro (cinco tomos, incluyendo el informe arqueológico), que antes de su publicación fue llamado "el libro blanco".

Pilar Calveiro (Calveiro, 2007) señala que cuando existe la intención de fijar un relato "oficial" ocurre una especie de corrimiento hacia el relato histórico, que siempre es único, más allá de su complejidad. En este caso la legitimación y la garantía de rigurosidad académica que brindaba la Universidad de la República a un informe oficial aumentaba las probabilidades de que ese relato pudiera "fijarse" y constituirse en el relato oficial y verdadero. ${ }^{19}$

Durante esta administración la narrativa anteriormente dominante pasa a ocupar el lugar de la "otra" narrativa al ser despojada de su lugar de legitimación oficial, ubicándose como el relato opositor, pero manteniendo la misma estructura argumentativa para explicar lo que sucedió, que se repite una y otra vez en los discursos oficiales, sean del signo que sean, referida a sustentar una lógica binaria de enfrentamiento entre iguales, que eventualmente pueden ser calificados de malos (los dos); buenos (los dos) o uno malo y el otro bueno.

Por otra parte, el intento de Vázquez de articular en un único discurso todos los discursos produjo el surgimiento de un relato confuso y contradictorio en el cual, como señalé antes, se mezclan conceptualizaciones diversas provenientes de perspectivas que se suponen en pugna. Este intento, además, hizo visibles las diferencias en el interior de la izquierda en torno a cómo se interpretaban y explicaban el pasado reciente y la violencia revolucionaria, lo que condujo, también, al resurgimiento de un relato militante y heroico que había estado presente en los primeros años de la transición.

\footnotetext{
${ }^{19}$ Más que analizar el contenido de las publicaciones realizadas por el equipo de investigación, lo que me importa destacar es la convocatoria a la academia por parte del gobierno para la realización de las investigaciones.
} 
Las otras memorias, que durante años fueron estigmatizadas y culpabilizadas desde el poder, surgían legitimadas por el accionar de un gobierno de izquierda, pero recolocándose nuevamente o en el lugar de víctima o en el lugar de héroe. La víctima y el héroe sustituían, otra vez, al actor político. En este último caso, la militancia era recuperada sin sentido crítico, produciéndose una inversión de la lógica de los dos demonios (Calveiro, 2007).

su anulación. El plebiscito se llevó a cabo junto con las elecciones nacionales y resultó perdedor. El impacto de esta segunda derrota no tuvo como resultado el silencio y el repliegue que ocurriera en los tempranos 90, luego del "voto verde", sino que, una vez asumido el gobierno de Mujica, comenzaron a discutirse dentro de la izquierda posibles salidas parlamentarias a la ley. Tras un debate arduo, complejo y cruzado por acusaciones de traición, la propuesta de votar una ley interpretativa que permitiera dejar sin efecto la 18.848 no alcanzó las mayorías requeridas al no contar con todos los votos de la coalición frenteamplista. ${ }^{20}$ La discusión parlamentaria, salvo excepciones, estuvo centrada, por una parte, en las formalidades jurídicas del proyecto de ley, y por otra en los alcances y límites de la soberanía popular. Las menciones al pasado reciente repitieron viejos modelos y la incorporación de elementos que complejizaran la mirada o que cuestionaran preceptos que provenían de narrativas supuestamente superadas estuvieron ausentes. Dice Álvaro Rico, en referencia a lo anterior:

"Pienso que el gran ausente en el debate parlamentario (...) fue el período de la dictadura. La discusión terminó girando sobre la convicción democrática o no de la izquierda, sin que el cuestionamiento a la dictadura estuviera presente cuando (...) la Ley de Caducidad y la discusión sobre la misma es una de las secuelas fundamentales del terrorismo de Estado (...). [A pesar de haberse avanzado por distintas vías] el discurso político y los argumentos jurídicos incorporan muy poco de ese conocimiento acumulado por la sociedad a través de (...) la investigación universitaria, el periodismo científico, el ensayo, las indagatorias de la justicia (...). Por ejemplo es muy sorprendente que luego de [las investigaciones encomendadas por la Presidencia de la República desde el año 2005] $]^{21}$ a la hora de fundamentar las interpretaciones de la ley (...) no [se] incorpora ninguno de estos resultados alcanzados. Estamos entonces frente a un discurso político autosostenido, que no necesita del referente histórico ni de pruebas para validarse. (...) (Rico, 2001, p. 4)

El análisis de ese largo y escabroso debate nos permite concluir que la construcción de un nuevo relato no logró consolidarse; el modelo explicativo e interpretativo del

\footnotetext{
${ }^{20}$ Esta situación produjo un quiebre al interior de la izquierda que aún no ha terminado de procesarse ni se ha analizado rigurosamente.

${ }^{21}$ Se refiere a los cinco tomos publicados por Presidencia de la República, elaborados por un equipo de investigadores de la UdelaR, coordinados por Álvaro Rico.
} 
pasado reciente continuó repitiendo la lógica impuesta a inicios de la transición por la teoría de los dos demonios. Por otro lado, los esfuerzos realizados desde el campo académico quedaron limitados y acotados a ese campo. Las publicaciones ${ }^{22}$ de Presidencia de la República (2007) y de la UdelaR (2009) que incorporaron nuevos datos y claves interpretativas sobre la represión estatal y sobre la estrategia de los grupos políticos y movimientos sociales que habían accionado durante la dictadura no produjeron ningún debate a nivel social o político que implicara una reflexión sobre lo sucedido.

Por su parte, los discursos producidos por José Mujica y por otros integrantes del Movimiento de Liberación Nacional-Tupamaros ${ }^{23}$ referidos a esta problemática manifiestan claramente la postura de una organización que adhiere a la lógica binaria de la teoría de los dos demonios, transformada ahora en la "teoría de los combatientes".

Mujica, como sujeto enunciador, construye una imagen de sí mismo a través de su discurso con la intención de que quien lo escucha construya a su vez una imagen de quién está hablando y desde el lugar desde dónde lo hace; esta construcción funciona como un argumento más que trasciende lo propiamente dicho. Este ethos discursivo lo ubica como un actor con fuerte legitimidad para hablar sobre lo sucedido, unificando en él el rol de presidente de la República, pero también su historia de excombatiente, otorgándole una especie de autoridad moral para, por ejemplo, hablar de la necesidad del perdón y del olvido.

En distintas oportunidades Mujica se ha autocalificado como "soldado", como combatiente que integró otro ejército en un momento, poniendo en pie de igualdad, de manera similar a lo que hacía Julio Ma. Sanguinetti, a ambos colectivos antagónicos: Fuerzas Armadas - Ejército Tupamaro.

Este relato impacta sobre el resto de la ciudadanía, reforzado por esa construcción del ethos: ¿quién puede tener mayor legitimidad para opinar sobre el pasado reciente y sobre lo "que hay que hacer" con él que alguien que sufrió no solo la cárcel y las torturas, sino que fue rehén de esa dictadura? ¿Quién, sino aquel que ha sido víctima directa de ese pasado?

Mujica regresa nuevamente con la obsesión por la unidad nacional pensada desde el olvido, enfatizando las menciones al perdón, la compasión y la construcción de la unidad nacional. ${ }^{24}$ La valoración negativa del conflicto no resulta una novedad, sino que, muy por el contrario, es un valor compartido por el resto del sistema político. Una

\footnotetext{
22 "Investigación histórica sobre detenidos-desaparecidos en cumplimiento del art. 4. ${ }^{\circ}$ de la Ley de Caducidad" y "Dictadura y terrorismo de Estado en Uruguay (1973-1985).

${ }^{23}$ Por ejemplo, la postura de la senadora Lucía Topolansky respecto de la liberación de los presos por crímenes de lesa humanidad mayores de 70 años: http://www.espectador.com/1v4_contenido.php?id=225042\&sts=1;

${ }^{24}$ Ver:http://archivo.presidencia.gub.uy/sci/noticias/2010/03/2010031609.htm; http://archivo.presidencia.gub.uy/sci/noticias/2011/05/2011051801.htm
} 
de las posibles consecuencias de este consenso es la exclusión del espacio público de temas de debate que podrían suponer la confrontación de opiniones distintas y "exacerbar las pasiones"; en ese sentido, las otras memorias son reconocidas pero se las coloca nuevamente al margen, acotándolas al lugar de lo privado, de lo familiar.

Se consolida de esta manera la perspectiva tradicional, enfatizándose las menciones al perdón, a la compasión y a la construcción de la unidad nacional. ${ }^{25}$

\section{Conclusiones}

La intención de este ensayo fue brindar un panorama general sobre los recorridos narrativos que se han construido en torno a los acontecimientos vinculados con la violencia política y la violación de los derechos humanos en el pasado reciente. Los límites del ensayo imposibilitan profundizar en las complejidades de cada una de estas construcciones y sus consecuencias, pero nos permiten brindar pistas y aventurar hipótesis que luego - eventualmente- podrían ser abordadas con mayor detenimiento.

En este último sentido, entiendo que, más allá de las transformaciones discursivas, de los intentos por unificar relatos, de las luchas por el pasado que han protagonizado los movimientos de derechos humanos y sectores políticos especialmente sensibles al tema, la narración predominante se ha construido a partir de las premisas de la teoría de los dos demonios. En oposición a ella han surgido relatos alternativos, se han producido disputas, y ha habido momentos en que podía pensarse en un cambio de narraciones, sobre todo en los inicios de la primera administración frenteamplista, cuando se incorporan elementos de la perspectiva del terrorismo de Estado, los que luego son nuevamente eclipsados por la otra perspectiva dominante.

Este discurso estereotipado y simplificado (Rico: 2011) se ha instalado en la sociedad y es reproducido ya no solo por los sectores de "derecha" o por los medios de comunicación, sino también por una parte importante de la izquierda, ampliando y profundizando su peso. A partir de la repetición sistemática de ciertos argumentos basados en la búsqueda de la paz, reconciliación y el perdón, una diversidad de actores (cada uno de ellos con sus propios motivos) cooperaron en la construcción de un vacío reflexivo sobre el pasado reciente que permite ocultar una imagen sobre el Uruguay y los uruguayos sobre la que no nos queremos interrogar.

\footnotetext{
${ }^{25}$ Estos discursos resultan contradictorios con una gestión en la que pueden registrarse importantes avances a nivel de leyes reparatorias y de respaldo a las investigaciones históricas y arqueológicas, así como la consolidación, reforzamiento y ampliación de las competencias de la Secretaría para los Derechos Humanos de la Presidencia de la República, ex-Secretaría de Seguimiento de la COMIPAZ. Un análisis más pormenorizado nos permitiría observar, en este caso, cómo la sanción que estableció la Corte Interamericana de $\mathrm{DDHH}$ determinó muchas de las decisiones políticas tomadas. Ver: http://www.presidencia.gub.uy/Comunicacion/comunicacionNoticias/discurso-mujica-21-de-marzo
} 


\section{BIBLIOGRAFÍA}

Bietti, Lucas M. (2008). Memoria, violencia y causalidad en la Teoría de los Dos Demonios. El Norte- Finnish Journal of Latin American Studies, 3, 1-31.

Calveiro, Pilar (2007). Los desafíos de la memoria. En Aguiluz M. y Waldman G. (coord.). Memorias (in)cógnitas. Contiendas en la historia. (237-256). México, DF: UNAM.

Crenzel, Emilio (2008). La historia política del Nunca Más. Buenos Aires: Editorial S. XXI.

Demasi, Carlos (2004). Un repaso a la teoría de los dos demonios. En Marchesi, A., Markarian, V., Rico, Álvaro, Yaffé, Jaime (comp.). El presente de la dictadura. Estudios y reflexiones a 30 años del golpe de Estado en Uruguay. (67-74). Montevideo: Trilce.

Gillis, John R. (1994). Memoria e Identidad: la historia de una relación. En www.cholonautas.edu.pe (consultado 10.06.2013).

Iglesias, Mariana (2010). El "Día del Nunca Más" en Uruguay (2006-2007): estrategias políticas y luchas interpretativas sobre la violencia política de los 60'-80'. En Lvovich, D., Bohoslavsky, E., Franco, M., Iglesias, M. (comp.). Problemas de historia reciente del Cono Sur, 1. (171-189). Buenos Aires: UNGS-Prometeo Libros.

Jelin, Elizabeth (2001) ¿De qué hablamos cuando hablamos de memorias? En Jelin, Elizabeth. Los trabajos de la memoria. (21-33). España: Siglo Veintiuno editores.

Pollak, Michel (2000). Memoria, olvido, silencio. Argentina: Ediciones Al Margen.

Rico, Álvaro (2011). Los alcances de la impunidad. Nuevas miradas. Noteolvides, 7, año 2. (4-7) Montevideo.

Roniger, Luis y Sznajder, Mario (2003). La reconstrucción de la identidad colectiva del Uruguay tras las violaciones de los derechos humanos por la Dictadura Militar. Araucaria, primer semestre. (1-31).

Sanguinetti, Julio María (2012). La Reconquista. Proceso de la restauración democrática en Uruguay (1980-1990). Montevideo: Editorial Taurus.

Vezzetti, Hugo (2002). Pasado y presente. Guerra, dictadura y sociedad en la Argentina. Buenos Aires: Siglo XXI Editores. 